\title{
Rapid increase in plasma endothelin concentrations during percutaneous balloon dilatation of the mitral valve in patients with mitral stenosis
}

Osamu Kinoshita, Hiroki Yoshimi, Seiki Nagata, Fuminobu Ishikura, Koji Kimura, Takashi Yamabe, Kenji Takagaki, Kunio Miyatake, Teruo Omae

\begin{abstract}
Objective-To investigate the relation between plasma concentrations of immunoreactive endothelin and haemodynamic variables before and after percutaneous transvenous balloon dilatation of the mitral valve.

Design-Prospective study.

Setting-National cardiovascular centre.
\end{abstract}

Patients-25 patients with mitral stenosis and 26 healthy volunteers.

Main outcome measures-Plasma concentrations of immunoreactive endothelin were measured in the pulmonary artery, left atrium, ascending aorta, and femoral vein before and after balloon dilatation of the mitral valve.

Results-Peripheral venous concentrations (mean (SD)) of endothelin were higher in the patients with mitral stenosis than in the healthy volunteers $(1.76$ $(0.51) v 1.37(0.45) \mathrm{pg} / \mathrm{ml}, \mathrm{p}<0.05)$ and they correlated with the mean left atrial pressure $(r=0.74, p<0.01)$. Balloon dilatation of the mitral valve reduced the mean left atrial pressure without changing the mean right atrial pressure, systemic arterial pressure, heart rate, or cardiac index. Concentrations of plasma endothelin in the femoral vein increased from $1.76(0.51)$ to $3.39(2.46)(p<0.01)$, $4.82(2.34)(p<0.001)$, and $2.43(0.52)$ $\mathrm{pg} / \mathrm{ml}(\mathrm{p}<0.05)$ at 15 and 30 minutes and 24 hours after the procedure. The concentration of endothelin in the pulmonary artery also increased from 1.85 $(0.85)$ to $4.32(1.58) \mathrm{pg} / \mathrm{ml}(\mathrm{p}<0.01) 30$ minutes after the dilatation, whereas there were no appreciable changes in endothelin concentration in the left atrium or ascending aorta.

Conclusions-Plasma endothelin concentrations were higher in patients with mitral stenosis than in healthy volunteers and the increase was proportional to left atrial pressure. After balloon dilatation of the mitral valve there was an abrupt rise in endothelin in the femoral vein and pulmonary artery but no change in left atrial or aortic blood samples. These findings suggest that endothelin may be another vasoactive substance involved in congestive heart failure.

(Br Heart f 1993;69:322-326)
Endothelin is an endothelium-derived peptide with 21 amino acid residues that is a potent vasoconstrictor. ${ }^{1}$ It may have a pathophysiological role in disorders associated with systemic and local vasoconstriction. ${ }^{2}$ Plasma endothelin concentrations were raised in various cardiovascular disorders-such as coronary vasospasm, ${ }^{3}$ subarachnoid haemorrhage ${ }^{4}$ Raynaud's phenomenon, ${ }^{5}$ and cardiogenic shock, ${ }^{6}$-all of which are characterised by local or peripheral vasoconstriction. Reports of plasma endothelin concentrations in congestive heart failure are not consistent. An increased plasma endothelin concentration was reported in humans ${ }^{7}$ and $\operatorname{dog} s^{89}$ with congestive heart failure, but in one study there was no appreciable increase of plasma endothelin concentration in patients with stable but severe congestive heart failure. Furthermore, in dogs with experimental congestive heart failure evoked by rapid ventricular pacing, plasma endothelin concentrations in the femoral artery were raised and correlated well with the mean pulmonary capillary wedge pressure. ${ }^{9}$ This finding accords with the primary role of left atrial pressure in cardiac atrial natriuretic peptide secretion in patients with mitral stenosis. ${ }^{1011}$ Recent observations demonstrate that endothelin is expressed in the lungs and heart as well as in vascular endothelial cells, ${ }^{12}{ }^{13}$ and the widespread distribution of endothelin mRNA indicates that the peptide can be synthesised in many tissues. ${ }^{14-16}$ These observations suggest that increased concentrations of plasma endothelin may be derived from the lungs or heart or both in states such as congestive heart failure. However, there is no information on the possible role of left atrial pressure in the secretion of endothelin from vascular endothelial cells. We studied the relations between plasma endothelin concentrations at multiple sampling sites and haemodynamic variables in patients with mitral stenosis undergoing percutaneous balloon dilatation of the mitral valve.

\section{Patients and methods}

PATIENTS AND BLOOD SAMPLING

We studied 25 patients (seven men and 18 women; mean (SD) age, 53 (10) years) with symptomatic mitral stenosis who were in New York Heart Association functional classes IIIII. They all gave their informed consent. Mitral stenosis was diagnosed by physical 
examination and echocardiography. Diuretics and digitalis were discontinued at least 24 hours before valve dilatation and all other medications, including sleeping pills and indigestion tablets were stopped at least 12 hours before the study. No patients had essential hypertension, ischaemic heart disease, or renal failure. In 17 patients the mitral valve was dilated with an Inoue balloon catheter by the transseptal Brockenbrough method. ${ }^{17}$ Haemodynamic variables including the pressures in the right atrium, right ventricle, pulmonary artery, left ventricle, left atrium, and ascending aorta, as well as the cardiac index were measured before and 30 minutes after valve dilatation. Blood samples were collected from the femoral vein, the pulmonary artery, left atrium and ascending aorta through a catheter and placed into ice-chilled tubes containing ethylenediamine tetra acetic acid $(1 \mathrm{mg} / \mathrm{ml}$ ) and aprotinin (500 kallikrein inactivation units $/ \mathrm{ml}$ ) before and, 15 and 30 minutes and 24 hours after balloon dilatation of the mitral valve.

The other eight patients underwent only diagnostic cardiac catheterisation and their femoral venous blood samples were obtained through a catheter before and immediately after the catheterisation to examine the effects of the catheterisation on the plasma concentration of immunoreactive endothelin.

We also collected blood samples through an antecubital vein from 26 apparently healthy volunteers (11 men and 15 women; mean (SD) age, 54 (8) years) without evidence of organic heart disease, essential hypertension, or renal failure.

\section{MEASUREMENT OF PLASMA ENDOTHELIN CONCENTRATION}

Plasma concentrations of immunoreactive endothelin were measured by a sensitive radioimmunoassay. ${ }^{13}$ In brief, a $4 \mathrm{ml}$ volume of plasma was acidified with $1 \mathrm{ml}$ of $0.5 \mathrm{~N}$ solution of hydrochloric acid and applied to a C8 octyl cartridge (Amersham, UK) which had been treated with $5 \mathrm{ml}$ of methanol and subsequently with $20 \mathrm{ml}$ of distilled water. After washing with $20 \mathrm{ml}$ of $0.1 \%$ trifluoroacetic acid, adsorbed materials were eluted from the cartridge with $3.5 \mathrm{ml}$ of $60 \%$ acetonitrile $/ 0 \cdot 1 \%$ trifluoroacetic acid, dried under a stream of nitrogen and reconstituted in $0.4 \mathrm{ml}$ of radioimmunoassay buffer. Standard endothelin-1 (Peptide Institute,

Table 1 Haemodynamic data (mean (SD)) before and after balloon dilatation of the mitral valve in 17 patients with mitral stenosis

\begin{tabular}{|c|c|c|c|}
\hline Data & Before & After & $p$ Value \\
\hline $\begin{array}{l}\text { Mitral valve orifice area }\left(\mathrm{cm}^{2}\right) \\
\text { Left atrial dimension }(\mathrm{mm}) \\
\text { Left ventricular diastolic dimension }(\mathrm{mm}) \\
\text { Left ventricular systolic dimension }(\mathrm{mm}) \\
\text { Mean right atrial pressure }(\mathrm{mm} \mathrm{Hg}) \\
\text { Mean pulmonary arterial pressure }(\mathrm{mm} \mathrm{Hg}) \\
\text { Mean left atrial pressure }(\mathrm{mm} \mathrm{Hg}) \\
\text { Mean systemic arterial pressure }(\mathrm{mm} \mathrm{Hg}) \\
\text { Heart rate }(\text { beats } / \mathrm{min}) \\
\text { Cardiac index }\left(1 / \mathrm{min} / \mathrm{m}^{2}\right)\end{array}$ & $\begin{array}{l}0 \cdot 97(0 \cdot 29) \\
50 \cdot 2(6 \cdot 8) \\
47 \cdot 4(4 \cdot 0) \\
33 \cdot 8(4 \cdot 5) \\
3 \cdot 8(2 \cdot 2) \\
25 \cdot 9(7 \cdot 4) \\
17 \cdot 2(5 \cdot 0) \\
91 \cdot 3(10 \cdot 7) \\
78 \cdot 1(16 \cdot 8) \\
2 \cdot 67(0 \cdot 49)\end{array}$ & $\begin{array}{l}1 \cdot 81(0 \cdot 38) \\
46 \cdot 1(6 \cdot 6) \\
46 \cdot 4(4 \cdot 2) \\
32 \cdot 9(4 \cdot 7) \\
2 \cdot 9(2 \cdot 9) \\
20 \cdot 9(8 \cdot 9) \\
10 \cdot 6(5 \cdot 3) \\
92 \cdot 8(14 \cdot 1) \\
77 \cdot 6(19 \cdot 6) \\
2 \cdot 87(0 \cdot 68)\end{array}$ & $\begin{array}{l}<0.001 \\
<0.01 \\
\text { NS } \\
\text { NS } \\
\text { NS } \\
<0.01 \\
<0.001 \\
\text { NS } \\
\text { NS } \\
\text { NS }\end{array}$ \\
\hline
\end{tabular}

Osaka, Japan) or the sample $(0.1 \mathrm{ml})$ was preincubated with anti-endothelin-1 rabbit serum (Peninsula, Belmont, Ca, USA) for 24 hours at $4^{\circ} \mathrm{C}$, followed by the addition of ${ }^{125} \mathrm{I}-$ endothelin-1 (Amersham, UK) and further incubation for 48 hours. Bound ${ }^{125}$ I-endothelin-1 was separated from free endothelin by the second antibody method. The smallest quantity of endothelin that was detectable was $0.5 \mathrm{pg} /$ tube, with $50 \%$ binding displacement at $15 \mathrm{pg} /$ tube. The mean recovery of 20 pg of authentic endothelin-1 after addition to plasma was $69 \cdot 7 \%$. The endothelin values were corrected for preparative losses. Crossreactivity of endothelin-1, endothelin-2, endothelin-3, and big endothelin-1 were 100 , $43 \cdot 1,13 \cdot 9$, and $5 \cdot 6 \%$, respectively.

\section{ECHOCARDIOGRAPHY}

$M$ mode echocardiograms were recorded by Toshiba echocardiographic system (160-A) and a strip chart recorder before and 24 hours after percutaneous balloon dilatation of the mitral valve. Patients were examined while recumbent with the probe placed from the third to the fifth intercostal spaces lateral to the left sternal border. Standard echocardiographic variables, including end diastolic and end systolic left ventricular dimensions and the left atrial dimension, were determined according to the recommendation of the American Society of Echocardiography..$^{18}$ The area of mitral valve orifice was calculated by planimetry from cross sectional echocardiograms (mean of 5-10 measurements).

\section{STATISTICAL ANALYSIS}

All data were expressed as mean (SD). The Student's unpaired $t$ test was used to compare the results in the controls and patients. Linear regression analysis was used to assess correlations between the plasma immunoreactive endothelin concentration and the haemodynamic variables. The changes of plasma endothelin concentrations in response to balloon dilatation were assessed by Student's paired $t$ test (before and 30 minutes after the procedure) and by one-way analysis of variance and Dunnett's $t$ test (before, 15 and 30 minutes after and 24 hours after the procedure). A probability value of less than 0.05 was regarded as statistically significant.

\section{Results}

\section{ECHOCARDIOGRAPHIC AND HAEMODYNAMIC}

\section{VARIABLES}

The area of mitral valve orifice increased significantly $(p<0.001)$ after balloon dilatation and the left atrial dimension decreased significantly $(p<0.001)$ (table 1$)$. There were no significant changes in the end diastolic or end systolic left ventricular dimension. The mean left atrial and pulmonary arterial pressures fell significantly in all the patients $(p<0.001$ and $\mathrm{p}<0.01$, respectively). However, there was no significant change in the mean right atrial pressure, mean systemic arterial pressure, heart rate, or cardiac index after the procedure. 
Figure 1 Changes (mean (SE)) in the concentration of immunoreactive endothelin in plasma from the femoral vein as a function of time after percutaneous transvenous balloon dilatation of the mitral valve in patients with mitral stenosis $(n=17)$.

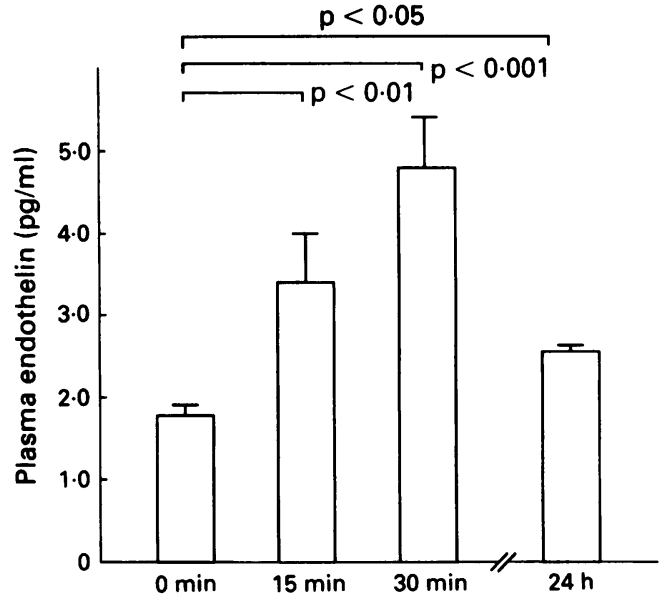

PLASMA IMMUNOREACTIVE ENDOTHELIN CONCENTRATIONS

Concentrations of immunoreactive endothelin in blood from the femoral vein increased from $1.76(0.51)$ to $3.39(2.46)(\mathrm{p}<0.01)$, $4.82(2.34)(\mathrm{p}<0.001)$, and $2.43(0.52)$ $\mathrm{pg} / \mathrm{ml}(\mathrm{p}<0.05)$ at 15 and 30 minutes and 24 hours after the procedure (fig 1). Similarly, the pulmonary arterial plasma immunoreactive endothelin concentration also increased from $1.85(0.85)$ to 4.32 $(1.58) \mathrm{pg} / \mathrm{ml}(\mathrm{p}<0.01)$ at 30 minutes after balloon dilatation whereas there were no appreciable changes in the plasma immunoreactive endothelin concentration in the left atrium or ascending aorta (table 2). Diagnostic cardiac catheterisation did not affect femoral venous plasma immunoreactive endothelin concentrations in eight patients with mitral stenosis $(1.78(0.45) \quad v \quad 1.81$ $(0.56) \mathrm{pg} / \mathrm{ml}, \mathrm{NS})$.

Before the procedure femoral venous plasma immunoreactive endothelin concentrations ranged from 0.85 to $2.43 \mathrm{pg} / \mathrm{ml}$ (mean $1.76(0.51) \mathrm{pg} / \mathrm{ml}$. Concentrations were slightly but significantly higher than those in blood from an antecubital vein in the healthy volunteers $(1.37(0.45) \mathrm{pg} / \mathrm{ml}, \mathrm{p}<0.05)$ (fig 2). There were no significant differences in the concentrations of plasma immunoreactive endothelin in the femoral vein, pulmonary artery, left atrium, and ascending aorta. Figure 3 shows there was a positive correlation between the mean left atrial pressure and the femoral venous plasma immunoreactive endothelin concentration in the patients before balloon dilatation of the mitral valve $(r=0.74, p<0.01)$.

Table 2 Plasma endothelin concentrations (mean (SD)) at various sampling sites before and after balloon dilatation of the mitral valve in 17 patients with mitral stenosis

\begin{tabular}{llll}
\hline Site & Before & After & p Value \\
\hline Femoral vein & $1.76(0.51)$ & $4.82(2.34)$ & $<0.001$ \\
Pulmonary artery & $1.85(0.85)$ & $4.32(1.58)$ & $<0.01$ \\
Left atrium & $1.81(0.47)$ & $1.83(0.50)$ & NS \\
Ascending aorta & $1.57(0.43)$ & $1.59(0.36)$ & NS \\
\hline
\end{tabular}

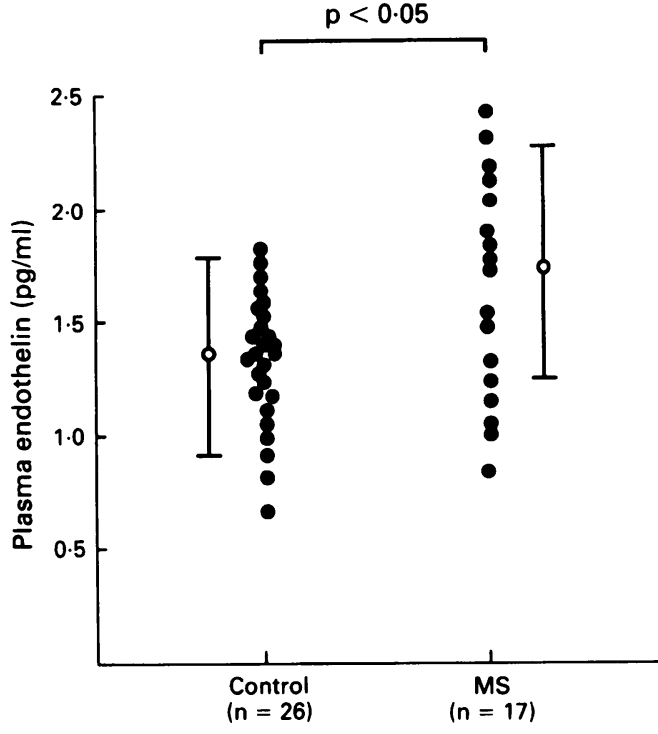

Figure 2 Concentrations (mean (SD)) of plasma immunoreactive endothelin in peripheral veins of 17 patients with mitral stenosis (MS) and 26 controls.

\section{Discussion}

We showed that peripheral venous concentrations of plasma immunoreactive endothelin in patients with symptomatic mitral stenosis were significantly higher than those in healthy volunteers. There was a positive correlation between the mean left atrial pressure and the concentration of endothelin in the femoral vein. These findings accord with the responded increase in plasma endothelin concentration in patients with congestive heart failure caused by various types of heart disease. ${ }^{7}$ In dogs with experimental congestive heart failure evoked by rapid ventricular pacing, the concentration of plasma endothelin in the femoral artery was increased and showed a positive correlation with the pulmonary capillary wedge pressure. ${ }^{9}$ The mechanism underlying this raised plasma endothelin concentration is uncertain. Plasma endothelin concentrations are increased in patients with pulmonary hypertension, ${ }^{6}{ }^{19}$ so the pulmonary hypertension associated with mitral stenosis may be a stimulus. Endothelin is expressed not only in vascular endothelial cells but also

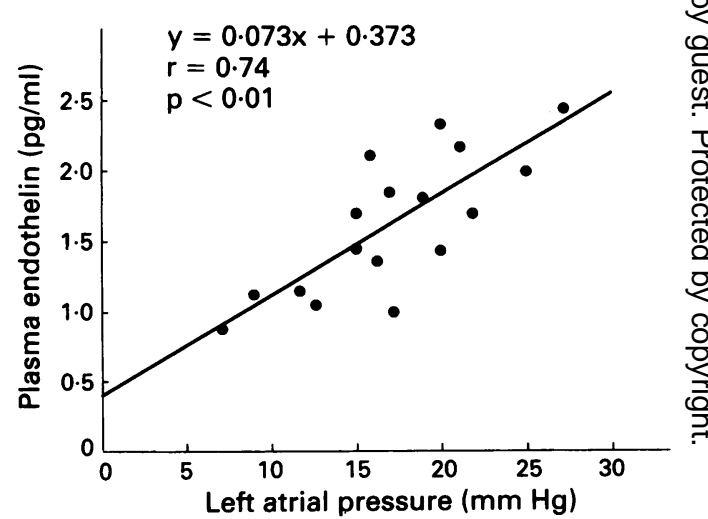

Figure 3 Correlation between mean left atrial pressure and plasma concentration of immunoreactive endothelin in the femoral vein of patients with mitral stenosis $(n=17)$.

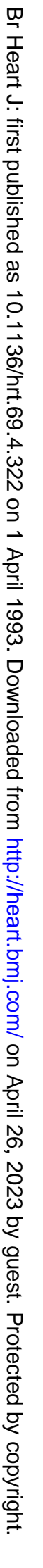


in other tissues, including the lungs and heart, ${ }^{12} 13$ and endothelin mRNA is widespread, indicating that the peptide may be synthesised in many tissues. ${ }^{14-16}$ This evidence suggests that endothelin may be related to congestive heart failure caused by mitral stenosis, because in congestive heart failure there is precapillary pulmonary hypertension and inappropriate peripheral vasoconstriction. Endothelin may be another vasoactive substance involved in congestive heart failure-like the cathecholamines and angiotensin II.

We found that percutaneous balloon dilatation of the mitral valve rapidly reduced left atrial pressure and caused a prompt increase in the plasma immunoreactive endothelin concentration in the femoral vein and pulmonary artery but not in the left atrium or ascending aorta. We showed that diagnostic cardiac catheterisation itself did not affect the plasma endothelin concentration in patients with mitral stenosis, suggesting that mechanical damage to vascular endothelial cells during the procedure was minimal. It is puzzling that balloon dilatation of the mitral valve increased the plasma endothelin concentration in venous blood but not in arterial blood. The relation between plasma endothelin concentration and the mean left atrial pressure before the procedure did not afford an explanation. There are several other possibilities.

First, haemodynamic or neurohormonal factors or both can stimulate the release of endothelin from vascular endothelial cells through the transient hypotension induced by the balloon inflation. There is a growing body of evidence suggesting that various factors can stimulate endothelin release from vascular endothelial cells, such as cardiogenic shock, ${ }^{6}$ systemic hypertension, ${ }^{2021}$ adrenaline, ${ }^{1}$ and angiotensin II. ${ }^{22}$ In our previous but similar clinical study in patients with mitral stenosis, however, plasma concentrations of noradrenaline and adrenaline and renin activity levels were not affected by balloon dilatation of the mitral valve. ${ }^{11}$ Also systemic blood pressure and heart rate did not change between before and 30 minutes after balloon dilatation of the mitral valve in the present study. Thus these factors are unlikely to be involved in the increase in plasma endothelin concentration induced by balloon dilatation.

Secondly, enhanced pulmonary extraction of circulating endothelin may be attributable to balloon dilatation of the mitral valve, which transiently increases left atrial pressure. In the present study we showed that the left atrial:pulmonary arterial ratio of the plasma immunoreactive endothelin concentration decreased from the basal value of 0.98 to 0.42 after balloon dilatation, indicating that the procedure increased pulmonary extraction of endothelin. An increase in the functional pulmonary vascular bed caused by balloon dilatation of the mitral valve may be related to this enhanced pulmonary extraction of endothelin. There is evidence of considerable pulmonary extraction of endothelin.
Intravenously injected endothelin disappeared after passage through the lungs in rats, ${ }^{23}$ and in healthy controls the endothelin concentration was higher in venous plasma than in arterial plasma: ${ }^{24}$

The more likely explanation seems to be a mechanism associated with the cardiopulmonary baroreceptor reflex. In dogs cardiopulmonary baroreceptors at various cardiopulmonary sites including the left atrium are activated by distension and exert a tonic inhibitory effect on sympathetic vasomotor outflow. ${ }^{25} 26$ Moreover, the concentration of endothelin in peripheral plasma increases in the standing position in humans, suggesting that secretion of endothelin from vascular endothelial cells may be regulated by changes in the extracellular fluid volume. ${ }^{27}$ However, this change could also be interpreted as an effect on the peripheral plasma endothelin concentration mediated by the cardiopulmonary baroreceptor reflex because the cardiopulmonary blood volume is reduced on standing and this inactivates the tonic inhibitory influence on the vasomotor centre. Congestive heart failure in humans and animals has been associated with the attenuation of cardiopulmonary baroreceptor control of circulation. ${ }^{2829}$ Therefore, it is tempting to speculate that the increase in venous endothelin concentrations after balloon dilatation of the mitral valve may reflect a compensatory increase in the release of endothelin from the local vascular bed in response to the impaired cardiopulmonary baroreceptor reflex. Animal studies performed with and without denervation of the afferent vagal nerves would be required to verify the involvement of cardiopulmonary baroreceptor reflexes in the increase of plasma endothelin concentrations occurring in response to a reduction of left atrial pressure.

We found that plasma immunoreactive endothelin concentrations were higher in patients with mitral stenosis than in normal controls and that the increase was proportional to left atrial pressure; that after balloon dilatation of the mitral valve, there was an abrupt rise in femoral venous and pulmonary arterial concentrations of immunoreactive endothelin but no change in left atrial or aortic blood samples. These findings suggest that endothelin may be another vasoactive substance, like the cathecholamines, angiotensin, and atrial natriuretic peptide.

This study was supported in part by a research grant for cardiovascular disease (1C-4) from the Ministry of Health and Welfare

1 Yanagisawa M, Kurihara H, Kimura S, et al. A novel potent vasoconstrictor peptide produced by vascular endothelial cells. Nature 1988;332:411-5.

2 Miller WL, Redfield MM, Burnett JC. Integrated cardiac, renal, and endocrine actions of endothelin. $\mathcal{F}$ Clin Invest 1989;83:317-20.

3 Toyo-oka T, Aizawa T, Suzuki N, et al. Increased plasma level of endothelin-1 and coronary spasm induction in patients with vasospastic angina pectoris. Circulation patients with vaso

4 Masaoka H, Suzuki R, Hirata Y, Emori T, Marumo F, Masaoka H, Suzuki R, Hirata Y, Emori T, Marumo F,
Hirakawa K. Raised plasma endothelin in aneurysmal Hirakawa K. Raised plasma endothelin in aneurys 5 Zamora MR, O'Brien RF, Rutherford RB, Weil JV. 
Serum endothelin-1 concentrations and cold provocation in primary Raynaud's phenomenon. Lancet 1990;336:1144-7.

6 Cernacek P, Stewart DJ. Immunoreactive endothelin in human plasma. Marked elevations in patients in cardiogenic shock. Biochem Biophys Res Commun 989;161:562-7.

7 Robertson RM, Susawa T, Sugiura M, Haile V, Inagami $\mathrm{T}$. Circulating endothelin levels. Modulation by heart failure in man. Clin Res 1990;38:414A

8 Cavero PG, Miller WL, Heublein DM, Aarhus LL, Burnett JC Jr. Endothelin in experimental congestive heart failure in the anesthetized dog. Am $\mathcal{f}$ Physiol 1990;259:F312-7.

9 Margulies KB, Hildeband FL Jr., Lerman A, Perrella MA, Burnett JC Jr. Increased endothelin in experimental heart failure. Circulation 1990;82:2226-30.

10 Yoshimi H, Inoue I, Hirata Y, et al. Atrial natriuretic peptide secretion in mitral stenosis. Am $\mathcal{f}$ Cardiol 1987;60:396-7.

11 Ishikura F, Nagata S, Hirata Y, et al. Rapid reduction of plasma atrial natriuretic peptide levels during percutaneous transvenous mitral commissurotomy in
with mitral stenosis. Circulation 1989;79:47-50.

12 Kitamura K, Yanaka T, Kato J, Eto T, Tanaka K Regional distribution of immunoreactive endothelin in porcine tissues: abundance in inner medulla of kidney. Biochem Biophys Res Commun 1989;161:348-52.

13 Yoshimi H, Hirata Y, Fukuda Y, et al. Regional distribution of immunoreactive endothelin in rats. Peptides 1989;10:805-8.

14 Giaid A, Polak JM, Gaitonde V, et al. Distribution of endothelin-like immunoreactivity and mRNA in the developing and adult human lung. Am $\mathcal{f}$ Respir Cell $\mathrm{Mol}$ Biol 1991;4:50-8.

15 MacCumber MW, Ross CA, Glaser BM, Snyder SH Endothelin: Visualization of mRNAs by in situ hybridization provides evidence for
Natl Acad Sci USA 1989;86:7285-9.

16 Nenez DJR, Brown MJ, Davenport AP, Neylon DB, Schofield JP, Wyse RK. Endothelin-1 mRNA is widely expressed in porcine and human tissues. $\mathcal{F}$ Clin Invest 1990;85:1537-41.

17 Inoue K, Owaki T, Nakamura T, Kitamura F, Miyamoto N. Clinical application of transvenous mitral commissurotomy by a new balloon catheter. $f$ Thorac Cardiovasc
Surg 1984;87:394-402.

18 Sahn DJ, DeMaria A, Kisslo J, Weiman A. The committee on M-mode standardization of the American Society of Echocardiography: results of a survey of echocardiographic measurements. Circulation 1978;58:1072-83.

19 Stewart DJ, Levy RD, Cernacek P, Langleben D. Increased plasma endothelin-1 in pulmonary hypertension: marker or mediator of disease? Ann Intern Med 1991;114:464-9.

20 Kohno M, Yasunari K, Murakawa K, et al. Plasma immunoreactive endothelin in essential hypertension. Am $\mathcal{F}$ Med 1990;88:614-8.

21 Shichiri M, Hirata Y, Ando K, et al. Plasma endothelin levels in hypertension and chronic renal failure. Hypertension 1990;15:493-6.

22 Emori T, Hirata Y, Ohta K, Shichiri M, Marumo F. Secretory mechanism of immunoreactive endothelin in cultured bovine endothelial cells. Biochem Biophys Res Commun 1989;160:93-100.

23 de Nucci $G$, Thomas $R$, D'Orleans-Juste $P$, et al. Pressor effects of circulating endothelin are limited by its removal in the pulmonary circulation and by the release of prostacyclin and endothelin-derived relaxing factor. Proc Natl Acad Sci USA 1988;85:9797-800.

24 Waner OF, Nowotny $P$, Vierhapper $H$, Waldhäusl $W$. agner OF, Nowotny $P$, Vierhapper $\mathrm{H}$, Waldhäusl W.
Plasma concentrations of endothelin in man: arteriovenous differences and release during venous stasis. Eur f Clin Invest 1990;20:502-5.

25 Mancia G, Donald DE. Demonstration that the atria, ventricles, and lungs each are responsible for a tonic inhibition of the vasomotor center in the dog. Circ Res 1975;36:310-8.

26 Zehr JE, Hasbargen JA, Kurz KD. Reflex suppression of renin secretion during distension of cardiopulmonary receptors in dogs. Circ Res 1976;38:232-9.

27 Shichiri $M$, Hirata $Y$, Ando $K$, et al. Postural change and volume expansion affect plasma endothelin levels. FAMA 1990;263:661.

28 Ferguson DW, Abboud FM, Mark AL. Selective impairment of baroreflex-mediated vasoconstrictor responses in patients with ventricular dysfunction. Circulation 1984;69:451-60.

29 Zucker IH, Earle AM, Gilmore JP. The mechanism of adaptation of left atrial stretch receptors in dogs with chronic congestive heart failure. $\mathcal{f}$ Clin Invest 1977;60:323-31. 